\title{
The 2-isocyanoazulene-gold(I) fragment as a versatile element for organometallic dyes and liquid crystals
}

Estela de Domingo, María Barcenilla, Jose Miguel Martín-Alvarez, Jesús A. Miguel and Silverio Coco*

IU CINQUIMA/Química Inorgánica, Facultad de Ciencias, Universidad de Valladolid, 47071 Valladolid, Castilla y León, Spain.

*Author to whom correspondence should be addressed. E-mail: scoco@qi.uva.es

Keywords: Azulene; Isocyanide; Organometallic dyes; Gold; Liquid crystals.

\begin{abstract}
This manuscript reports the synthesis and liquid crystal behavior of isocyanoazulene gold(I) complexes $[\mathrm{AuX}(\mathrm{CN}-\mathrm{Az})](\mathrm{Az}=$ azulene; $\mathrm{X}=$ halide, perhalophenyl or alkynyl) and $[\mu-$ $\left.4,4^{\prime}-\mathrm{C}_{6} \mathrm{~F}_{4} \mathrm{C}_{6} \mathrm{~F}_{4}\{\mathrm{Au}(\mathrm{CN}-\mathrm{Az})\}_{2}\right]$. The comparison of the X-ray structures of homologous compounds, reveals that the introduction of a long substituent in the system produces a loss of molecular planarity that induces a decrease in the melting temperatures. The free 2isocyanoazulene is not a liquid crystal itself, but its gold complexes bearing a $\mathrm{C}_{10}$ hydrocarbon chain display a SmA mesophase, whose formation is driven by nanosegregation between molten chains and aromatic parts. The free isocyanide is strongly colored and displays fluorescence in solution associated with the azulene fragment, which is largely diminished upon coordination to the gold fragment.
\end{abstract}




\section{Introduction}

Azulene, a classical azure-blue chromophore with a large permanent dipole moment, is an attractive building block for the construction of advanced organic materials [1], including conducting polymers [2], nonlinear optical materials $[3,4]$, molecular sensors [57], advanced materials for optoelectronic [8-11], and liquid crystals [12-17]. Azulene derivatives are also gaining interest in medicine and pharmacology [18-20], as well as in the cosmetic industry [21].

All these applications rely on rational modification of the molecular properties by the substitution patterns of five- and seven-membered azulene rings [22-26]. There are many reports on the effects of introducing different types of organic substituents in the azulene core. However, the number of studies for inorganic substituents is lower [27-35]. The majority of them are metal complexes involving multi-hapto coordination of the azulenic framework to the metal [28-31], or azuliporphyrin derivatives [32-35].

A straightforward strategy to modulate the properties of azulene systems using metal synthons, is the functionalization of the azulene core with coordinating groups that can act as ligands for metal complex formation. In this regard, isocyanides are versatile ligands that form stable organometallic complexes with most transition metals [36,37]. Isocyanide metal complexes are of long-standing importance in catalysis [38], diagnostic medicine [39], and material science [40,41], including liquid crystals [42]. Surprisingly, the great potential of isocyanide derivatives has barely been exploited to modulate the properties of azulene systems [43]. Only recently, a few mononuclear isocyanoazulene metal complexes of $\mathrm{Cr}(0), \mathrm{W}(0), \mathrm{Cr}(\mathrm{I})$ and $\mathrm{Ru}(\mathrm{II})$ have been reported [44-48], as well as a series of heterobimetallic $\mathrm{Cr}(0) / \mathrm{Au}(\mathrm{I})$ complexes derived from 2-isocyano-6-mercaptoazulene [49]. 
On these grounds and as a part of our continuing research program on mesomorphic metal complexes, we decided to prepare 2-isocyanoazulene gold(I) complexes of the type $[\mathrm{AuX}(\mathrm{CN}-\mathrm{Az})](\mathrm{Az}=$ azulene; $\mathrm{X}=$ halide, perhalophenyl or alkynyl $)$ and $\left[\mu-4,4^{\prime}-\right.$ $\left.\mathrm{C}_{6} \mathrm{~F}_{4} \mathrm{C}_{6} \mathrm{~F}_{4}\{\mathrm{Au}(\mathrm{CN}-\mathrm{Az})\}_{2}\right]$, aiming not only at modifying the properties of the system, but also at exploring the applicability of these organometallic systems to prepare functional organometallic liquid crystals. We have obtained examples of 2-isocyanoazulene gold(I) complexes displaying liquid crystal behavior, of which, to the best of our knowledge, there are no examples reported.

\section{Results and Discussion}

\subsection{Synthesis and Characterization}

The isocyanide complexes $[\mathrm{AuX}(\mathrm{CN}-\mathrm{Az})](\mathrm{Az}=$ azulene $),\left(\mathrm{X}=\mathrm{Cl}(\mathbf{1}), \mathrm{C}_{6} \mathrm{~F}_{5}(\mathbf{2})\right.$, $\mathrm{C}_{6} \mathrm{~F}_{4} \mathrm{OC}_{8} \mathrm{H}_{17}(\mathbf{3}), \mathrm{C}_{6} \mathrm{~F}_{4} \mathrm{OC}_{10} \mathrm{H}_{21}(4), \mathrm{C}_{6} \mathrm{~F}_{4} \mathrm{C}_{6} \mathrm{~F}_{4} \mathrm{OC}_{10} \mathrm{H}_{21}(\mathbf{5}),\left[\mu-4,4{ }^{\prime}-\mathrm{C}_{6} \mathrm{~F}_{4} \mathrm{C}_{6} \mathrm{~F}_{4}\{\mathrm{Au}(\mathrm{CN}-\mathrm{Az})\}_{2}\right]$ (6) and $\left[\mathrm{Au}\left(\mathrm{C} \equiv \mathrm{C}-\mathrm{C}_{6} \mathrm{H}_{4}-\mathrm{R}\right)(\mathrm{CN}-\mathrm{Az})\right]\left(\mathrm{R}=\mathrm{COOCH}_{3}(\mathbf{7}), \mathrm{COOC}_{10} \mathrm{H}_{21}(\mathbf{8})\right)$ were synthesized by direct reaction of $\mathrm{CN}-\mathrm{Az}$ with the corresponding gold(I) precursor as depicted in Scheme 1. All the complexes were isolated as highly colored solids.

C, H, N analyses, yields, and relevant IR and NMR characterization data are given in the experimental part (SM). The IR spectra of the gold complexes exhibit one $v(C \equiv N)$ absorption at $c a .2206 \mathrm{~cm}^{-1}$ for the isocyanide group, which appears at higher wavenumbers than for the free ligand, as a consequence of coordination [50]. In addition, alkynyl complexes display the corresponding $v(\mathrm{C} \equiv \mathrm{C})$ absorption at around $2120 \mathrm{~cm}^{-1}$ for the alkynyl group. The ${ }^{1} \mathrm{H}$ NMR spectra show the characteristic pattern of the azulene group, similar to that of the free isocyanide ligand [47], as well as the corresponding 
resonances from the auxiliary ligands present in the complexes. The complete assignment of the signals is collected in the experimental part.

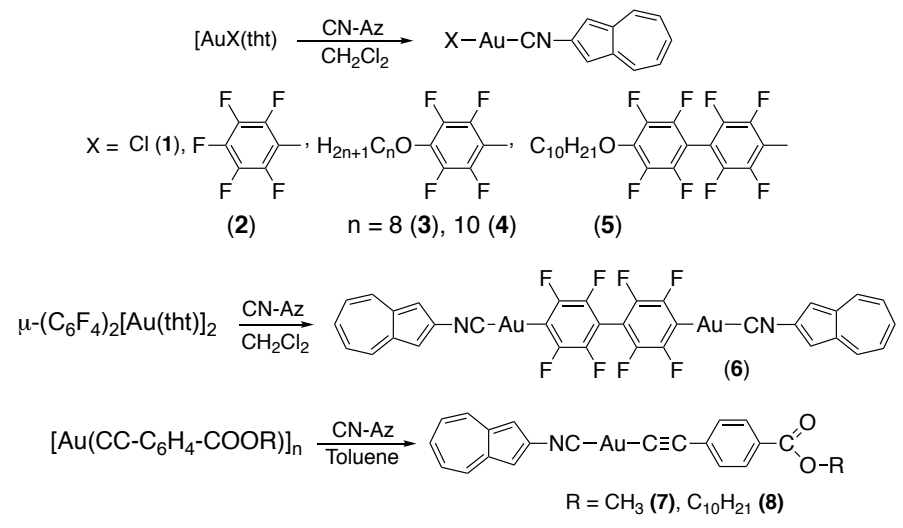

Scheme 1. Synthesis of 2-isocyano-azulene gold(I) complexes.

Similarly, the ${ }^{19}$ F NMR spectra of the fluorophenyl complexes 2-6 show the typical patterns of the corresponding fluorophenyl group: three resonances from an AA'MXX' spin system for the $\mathrm{C}_{6} \mathrm{~F}_{5}$ derivative [51]; two somewhat distorted pseudodoublets from a AA'XX' spin system, with $\mathrm{J}_{\mathrm{AA}}{ }^{\prime} \approx \mathrm{J}_{\mathrm{XX}}$, for the tetrafluorophenyl complexes [42]; four pseudodoublets from the two AA'XX' spin systems for the octafluorobiphenyl compound 5; and two complex multiplets at $-117.58 \mathrm{ppm}$ and $-141.50 \mathrm{ppm}$, corresponding to the ortho and the meta fluorine atoms of the two AA'XX' spin systems, for the 4,4'octafluorobiphenyl compound 6 [50].

\subsection{X-ray diffraction structures.}

Compounds 1-8 have been characterized by single crystal X-ray diffraction studies. The crystallographic data are summarized in Table S1-S3 in the Supporting Material, and the molecular structures are given in Figures 1 and S1.

All the complexes show a nearly linear geometry for gold. Bond angles and bond lengths fall within normal ranges [52-57]. The shortest and the longest $\mathrm{Au}-\mathrm{C}^{(\mathrm{CN})}$ distances 
correspond to $1(1.920(11) \AA)$ and 8 (1.970(7) $\AA$ ), respectively, according to the lowest trans-influence of $\mathrm{Cl}^{-}$and the highest trans-influence of the $\mathrm{RC}_{2}^{-}$group, compared to the other ligands.

The mononuclear isocyanide complexes without a long substituent $(\mathbf{1 , 2}$, and $\mathbf{7})$ have a planar structure, where the azulene group and the aromatic ring of the coligand $\left(\mathrm{C}_{6} \mathrm{~F}_{5}\right.$, - CC$\left.\mathrm{C}_{6} \mathrm{H}_{4}-\mathrm{COOCH}_{3}\right)$ are practically coplanar. In contrast, in their analogous complexes bearing a long chain $(3,4)$, the mean planes of the two ligands are twisted relative to each other, losing the molecular planarity. The same goes for the octafluorobiphenyl derivatives $(\mathbf{5}, \mathbf{6})$, where the two aryl rings of the octafluorobiphenyl system make a dihedral angle of about $53.7^{\circ}$. For 8, both types of structure, planar (dihedral angle of $4,6^{\circ}$ ) and non-planar $\left(59.4^{\circ}\right)$, coexist in the crystal (Figure S5).

The alkyl or alkoxy chains are extended in all the complexes, but form a different angle with the long molecular axis. In 3 the alkoxy chain is almost collinear $\left(8.6^{\circ}\right)$ with the best line formed by the atoms $\mathrm{C}^{(\text {(azulene) }}-\mathrm{N} \equiv \mathrm{C}-\mathrm{Au}-\mathrm{C}^{(\text {(coligand) }}$, whereas in 4,5 and $\mathbf{8}$, the extended chain makes a higher angle $\left[38.5^{\circ}(\mathbf{4}), 16.9^{\circ}(5)\right.$ and $51^{\circ}$ (planar molecule of 8 )] giving rise to a bent molecular shape (Figures 1, S2 and S5).

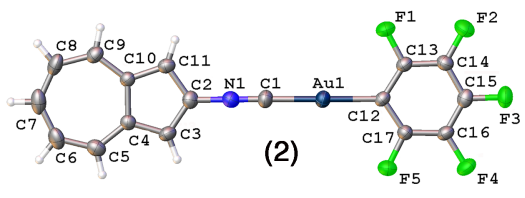

(3)

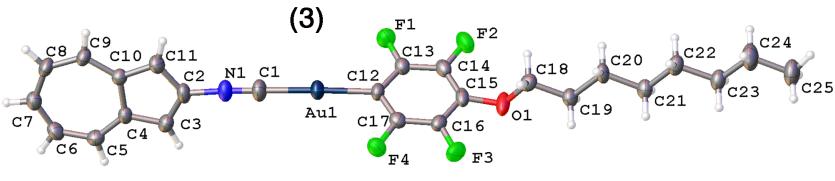



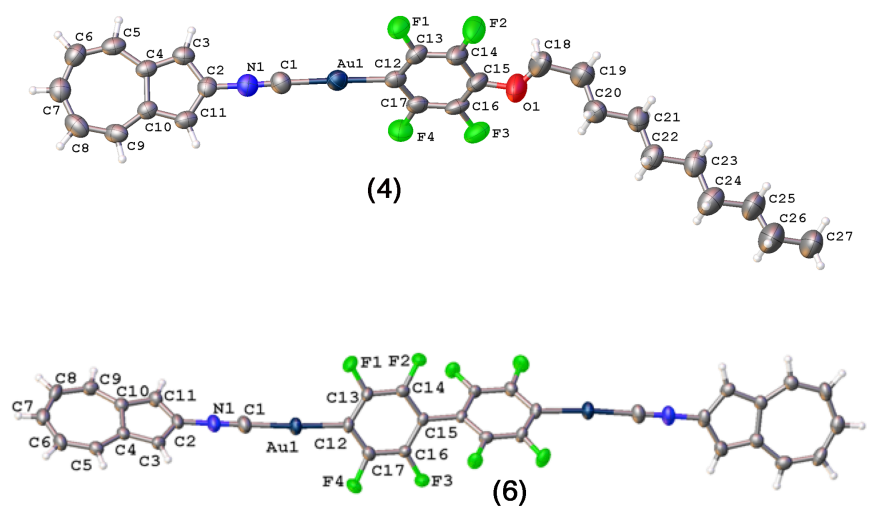

Figure 1. Crystal structures of 2-4 and 6 with thermal ellipsoids at 50\% probability.

The organization of the individual molecules in each solid differs. The crystal packing representations of all the compounds, as well as some of their intermolecular features, are displayed in Figures 2-5 and S2-S5.

The crystal packing of $\mathbf{1}$ exhibits a polymeric zigzag chain of antiparallel molecules linked via $\mathrm{Au} \cdots \mathrm{Au}$ interactions (3.435 $\AA$ ) (Figure 2). The polymer chains are additionally cross-linked through $\mathrm{Au} / \pi$ contacts, as reported for $\left[\mathrm{AuCl}\left(\mathrm{CNC}_{6} \mathrm{H}_{4}-\mathrm{C}_{n} \mathrm{H}_{2 n+1}\right)\right]$ [58].
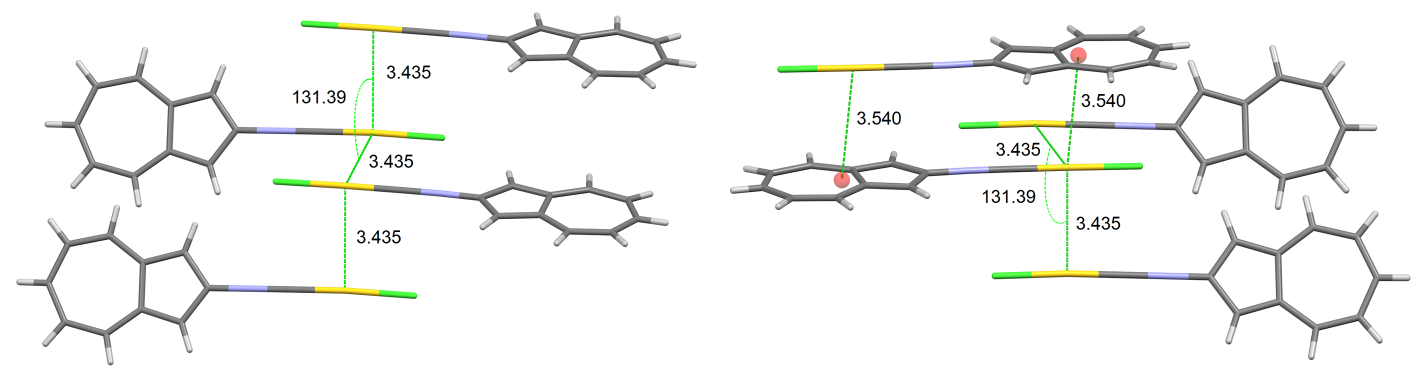

Figure 2. Partial view of crystal packing of 1 showing the infinite zigzag chain with $\mathrm{Au} \cdots \mathrm{Au}$ distances of $3.435 \AA$ (left), and $\mathrm{Au} / \pi$ contacts between the zigzag chains (right). Centroids of aromatic rings are shown as red circles and the centroid $\cdots$ Au distance is 3.540 Å. Color code: $\mathrm{C}$, dark gray; N, blue; Au, yellow; $\mathrm{Cl}$, lime green and $\mathrm{H}$, gray.

In 2 , the molecules self-associate in pairs through $\mathrm{Au} \cdots \mathrm{Au}$ interactions $(3.46 \AA)$ and $\pi \cdots \pi$ interactions between pentafluorophenyl groups (3.613 $\AA$ ), as well as between azulene moieties (3.754 $\AA$ ). These dimers further interact by intermolecular $\pi \cdots \pi$ interactions 
between azulene and pentafluorophenyl groups of neighboring molecules of contiguous pairs (3.485 $\AA$ ) (Figure 3). A similar packing but with the molecules arranged in an antiparallel disposition is found for 7 (Figure S4).

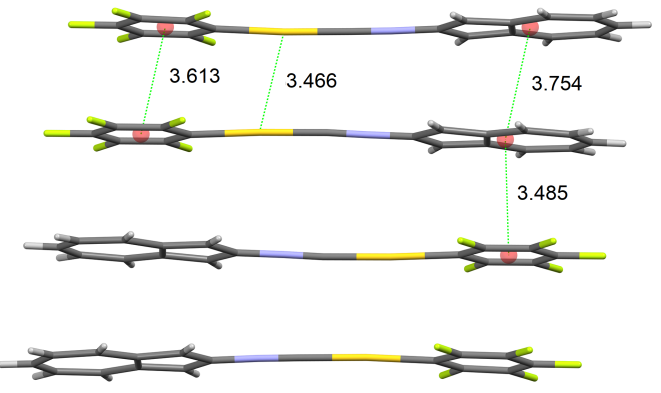

Figure 3. Partial view of crystal packing of $\mathbf{2}$ displaying the antiparallel arrangement of dimers and their intermolecular features. Color code as figure 2.

In 3 there are not aurophilic interactions because the shortest distance between gold atoms is $6.384 \AA$. However, the molecules are associated side by side in layers by short C$H^{\cdots} \pi$ contacts $(2.875 \AA$ ) (Figure 4$)$. Each molecule is shifted from the previous producing an interpenetration of aromatic and aliphatic parts. Additionally, these layers are linked through $\mathrm{F}_{\text {ortho }} \cdots \mathrm{H}(9)$ intermolecular contacts (2.564 $\AA$ ). Similar packing with cross-linked layers was also found in 6 (Figure S3).

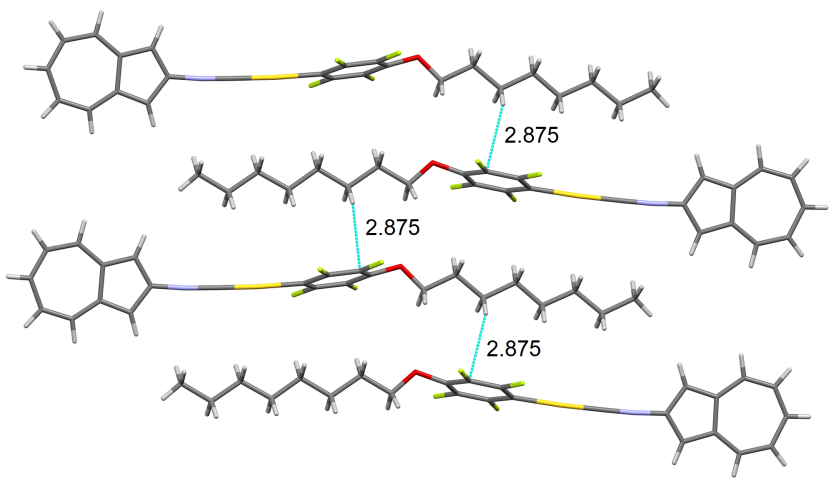




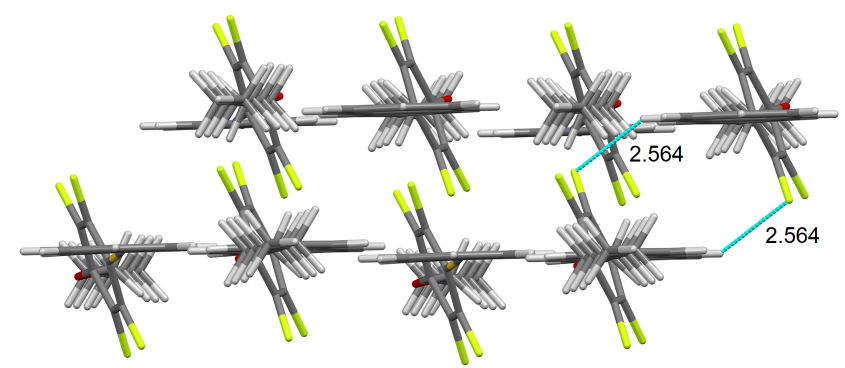

Figure 4 Partial view of crystal packing of 3. (up) View perpendicular to the director of the molecules showing the $\mathrm{C}-\mathrm{H} \cdots \pi$ contacts which define the layers. (down) View parallel to the director (long axis) of the molecules, showing the $\mathrm{C}-\mathrm{H} \cdots \mathrm{F}$ contacts between layers. Color code: $\mathrm{C}$, dark gray; $\mathrm{N}$, light blue; $\mathrm{O}$, red; Au, yellow; F green and $\mathrm{H}$, gray.

The crystal packing of complex $\mathbf{4}$, which is homologous to $\mathbf{3}$ but bearing a decyloxy substituent, shows stacking of molecules in a parallel disposition, but each molecule is shifted from the previous one, so that the shortest intermolecular distance observed is 2.648 $\AA$ between one $\mathrm{F}_{\text {ortho }}$ and a $\mathrm{H}$ atom of the $\beta-\mathrm{CH}_{2}$ group of the alkoxy chain. Considering that the sum of the van der Waals radii of $\mathrm{H}$ and $\mathrm{F}$ is $2.67 \AA$, the intermolecular $\mathrm{H}-\mathrm{F}$ distance observed would exclude the existence of any significant covalent $\mathrm{H} \cdots \mathrm{F}$ interaction, but not the contribution of an electrostatic interaction at the exclusion distance of the aryl rings. This might be the reason for the antiparallel arrangement of the stackings (Figure 5). It is worth noting that the aromatic parts and the alkoxy chains are segregated giving rise to a layered structure with the long molecular axes mainly orthogonal to the layers. This type of segregation is also observed in $\mathbf{5}$ and $\mathbf{8}$ (Figures S2 and S5), that is the complexes that show mesomorphic behavior, as discussed below.

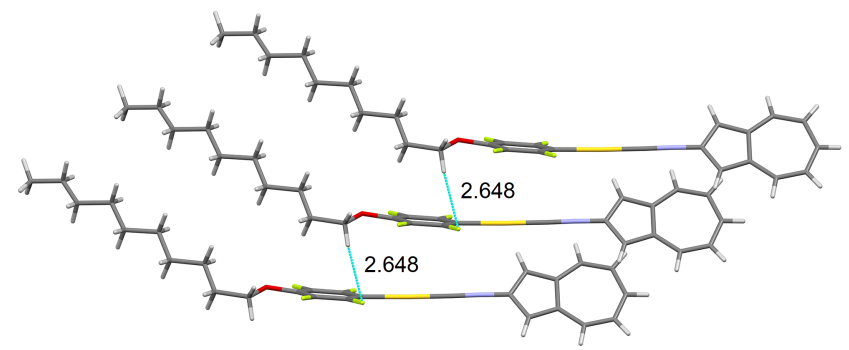




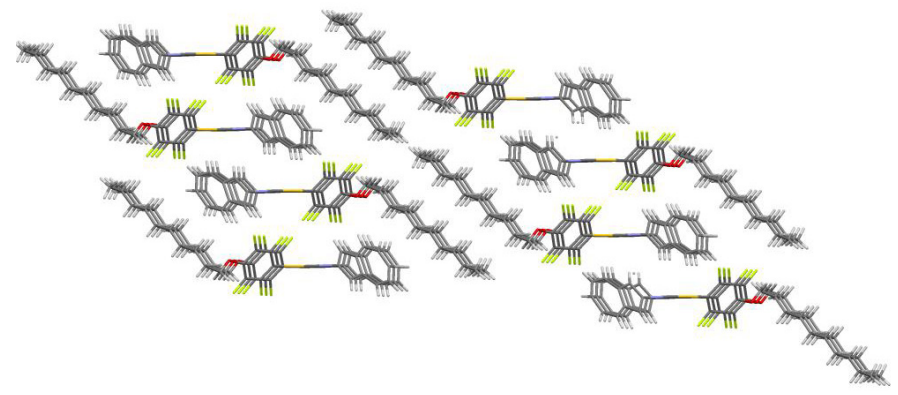

Figure 5. Partial view of crystal packing of 4 . The presence of the long alkyl chain in 4 promoted the segregation of the alkyl chains from the aromatic cores.

\subsection{Thermal behavior and self-organization properties.}

The mesomorphic properties have been studied by polarized optical microscopy (POM) and differential scanning calorimetry (DSC). The optical, thermal and thermodynamic data are gathered in Table 1 and Figures S44-S52. The isocyanide gold complexes lacking a long substituent $(\mathbf{1}, \mathbf{2}, \mathbf{6}$ and 7$)$ melt directly to an isotropic liquid, as it is also the case for complex 3, with a $\mathrm{C}_{8}$ chain. However, although the free 2-isocyanoazulene is not a liquid crystal itself, the gold complexes $\mathbf{4}, \mathbf{5}$ and $\mathbf{8}$, bearing a $\mathrm{C}_{10}$ hydrocarbon chain, display mesomorphic behavior.

Table 1. Optical, thermal, and thermodynamic data for the free isocyanide and the gold(I) complexes.

\begin{tabular}{|c|c|c|c|}
\hline Compound & Transition $^{\mathrm{a}}$ & $\begin{array}{l}\text { Temperature } \\
\left({ }^{\circ} \mathrm{C}\right)\end{array}$ & $\begin{array}{l}\Delta \mathrm{H}^{\mathrm{b}} \\
\left(\mathrm{kJmol}^{-1}\right)\end{array}$ \\
\hline Isocyanide & $\mathrm{Cr} \rightarrow \mathrm{I}$ & 70 & 8.2 \\
\hline$[\mathrm{AuCl}(\mathrm{CN}-\mathrm{Az})]$ & $\mathrm{Cr} \rightarrow \mathrm{dec}^{\mathrm{c}}$ & 203 & \\
\hline$\left[\mathrm{Au}\left(\mathrm{C}_{6} \mathrm{~F}_{5}\right)(\mathrm{CN}-\mathrm{Az})\right]$ & $\mathrm{Cr} \rightarrow \mathrm{dec}^{\mathrm{c}}$ & 220 & 22.1 \\
\hline$\left[\mathrm{Au}\left(\mathrm{C}_{6} \mathrm{~F}_{4} \mathrm{OC}_{8} \mathrm{H}_{17}\right)(\mathrm{CN}-\mathrm{Az})\right]$ & $\mathrm{Cr} \rightarrow \mathrm{I}$ & 79 & 17.8 \\
\hline$\left[\mathrm{Au}\left(\mathrm{C}_{6} \mathrm{~F}_{4} \mathrm{OC}_{10} \mathrm{H}_{21}\right)(\mathrm{CN}-\mathrm{Az})\right]$ & $\begin{array}{l}\mathrm{Cr} \rightarrow \mathrm{SmA} \\
\mathrm{SmA} \rightarrow \mathrm{I}\end{array}$ & $\begin{array}{l}76 \\
88\end{array}$ & $\begin{array}{l}14.6 \\
2.1\end{array}$ \\
\hline$\left.\left[\mathrm{Au}\left\{\left(\mathrm{C}_{6} \mathrm{~F}_{4}\right)_{2} \mathrm{OC}_{10} \mathrm{H}_{21}\right)\right\}(\mathrm{CN}-\mathrm{Az})\right]$ & $\mathrm{Cr} \rightarrow \mathrm{SmA} \rightarrow \mathrm{I}$ & 162 & $18.8^{\mathrm{d}}$ \\
\hline$\left[\left(\mu-4,4^{\prime}-\mathrm{C}_{6} \mathrm{~F}_{4} \mathrm{C}_{6} \mathrm{~F}_{4}\right)\{\mathrm{Au}(\mathrm{CN}-\mathrm{Az})\}_{2}\right]$ & $\mathrm{Cr} \rightarrow \mathrm{dec}^{\mathrm{c}}$ & 240 & \\
\hline$\left[\mathrm{Au}\left(\mathrm{CCC}_{6} \mathrm{H}_{4} \mathrm{COOCH}_{3}\right)(\mathrm{CN}-\mathrm{Az})\right]$ & $\mathrm{Cr} \rightarrow \mathrm{dec}^{\mathrm{c}}$ & 182 & \\
\hline$\left[\mathrm{Au}\left(\mathrm{CCC}_{6} \mathrm{H}_{4} \mathrm{COOC}_{10} \mathrm{H}_{21}\right)(\mathrm{CN}-\mathrm{Az})\right]$ & $\begin{array}{l}\mathrm{Cr} \rightarrow \mathrm{SmA} \\
\mathrm{SmA} \rightarrow \mathrm{dec}\end{array}$ & $\begin{array}{l}106 \\
150\end{array}$ & 27.2 \\
\hline
\end{tabular}


${ }^{a} \mathrm{Cr}$, crystal phases; SmA, smectic A mesophase; I, isotropic liquid; dec, decomposition. ${ }^{\mathrm{b}}$ Data collected from the second heating DSC cycle. The transition temperatures are given as peak onsets. ${ }^{\mathrm{c}}$ Data collected from the first heating DSC cycle. ${ }^{\mathrm{d}}$ Combined enthalpies.

Regarding the thermal stability of the compounds studied, thermogravimetric analysis performed in a thermobalance by heating it up to $800{ }^{\circ} \mathrm{C}$ under $\mathrm{N}_{2}$ shows a good thermal stability up to temperatures above $200{ }^{\circ} \mathrm{C}$ (Figures S53-S60).

All the mesomorphic gold complexes display only a smectic A mesophase (SmA). This is a very common mesophase in calamitic liquid crystals, identified in polarized optical microscopy by its typical myelinic and homeotropic textures on heating from the crystal phases, and the focal-conic fan texture on cooling from the isotropic phases $[59,60]$ (Figure $6)$.
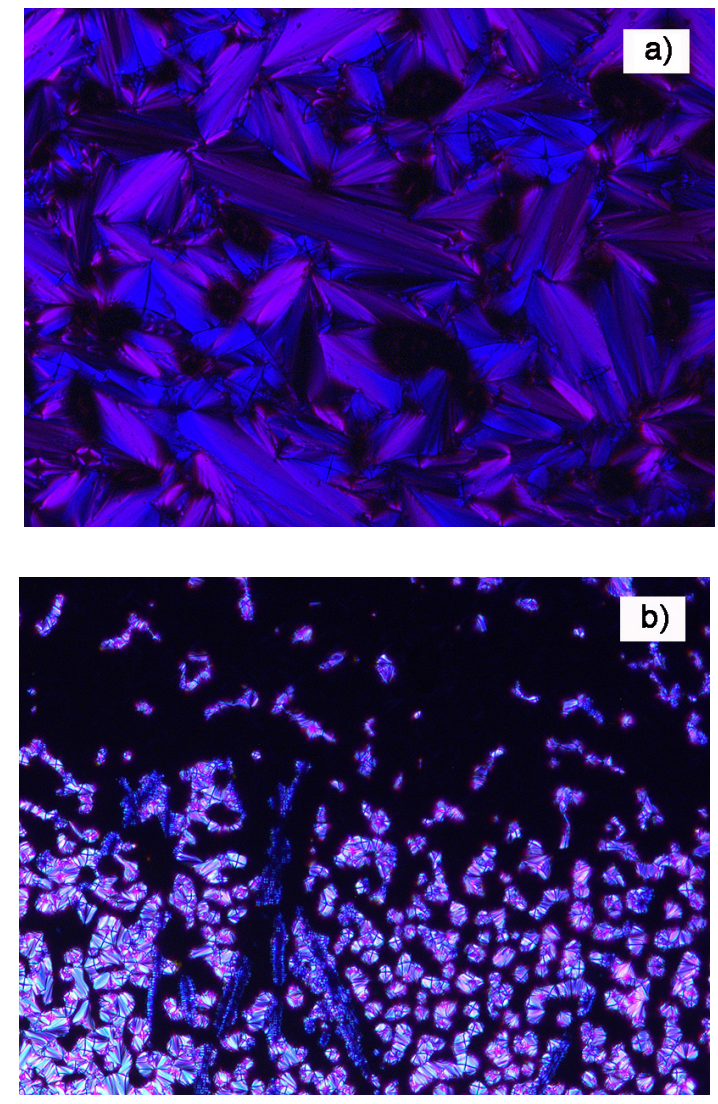


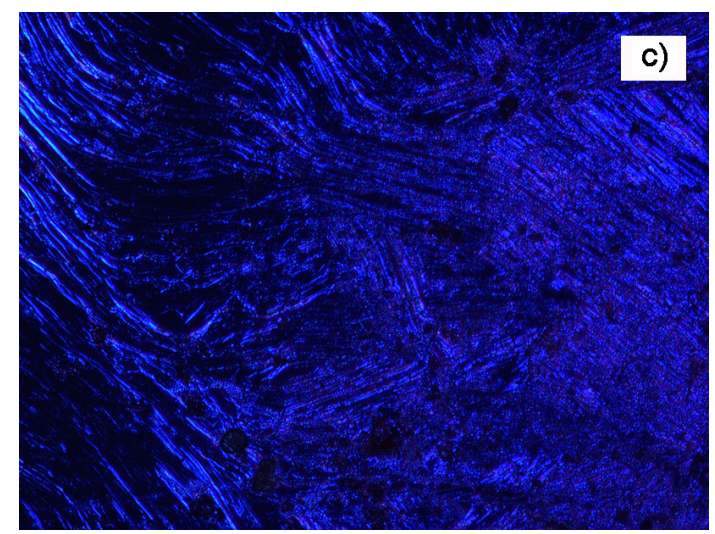

Figure 6. Optical polarizing microscopy photographs (x 100) of: a) $\left[\mathrm{Au}\left(\mathrm{C}_{6} \mathrm{~F}_{4} \mathrm{OC}_{10} \mathrm{H}_{21}\right)(\mathrm{CN}-\mathrm{Az})\right](4)$ at $83{ }^{\circ} \mathrm{C}$ on cooling from the isotropic liquid; $\left.b\right)$ $\left[\mathrm{Au}\left(\mathrm{C}_{6} \mathrm{~F}_{4} \mathrm{C}_{6} \mathrm{~F}_{4} \mathrm{OC}_{10} \mathrm{H}_{21}\right)(\mathrm{CN}-\mathrm{Az})\right](5)$ at $156^{\circ} \mathrm{C}$ on cooling from the isotropic phase; and $\left.\mathrm{c}\right)$ $\left[\mathrm{Au}\left(\mathrm{C} \equiv \mathrm{C}-\mathrm{C}_{6} \mathrm{H}_{4}-\mathrm{COOC}_{10} \mathrm{H}_{21}\right)(\mathrm{CN}-\mathrm{Az})\right](\mathbf{8})$ at $126{ }^{\circ} \mathrm{C}$ on heating from the crystal phase. Crossed polarizers.

In order to confirm the lamellar nature of the SmA mesophases, XRD studies were performed for compound $\left[\mathrm{Au}\left(\mathrm{C}_{6} \mathrm{~F}_{4} \mathrm{OC}_{10} \mathrm{H}_{21}\right)(\mathrm{CN}-\mathrm{Az})\right]$ (4), selected as a representative example. The diffractogram recorded at $80{ }^{\circ} \mathrm{C}$ shows three peaks in the low angle region with a $d$-spacing ratio of 1:1/2:1/3 (001, 002 and 003 reflections), followed by the typical halo at $c a \cdot 20^{\circ}(4.3 \AA)$ corresponding to the molten alkyl chains (Figure 7). The lamellar periodicity $\left(\mathrm{d}_{1}\right)$ is $33.6 \AA$, which is longer than the estimated all-trans length of the molecule $(\mathrm{L}=28.3)$ with a $\mathrm{d}_{1} / \mathrm{L}$ ratio $\sim 1.2$ signifying a partial bilayer structure. These gold compounds possessing a complex multipolar structure can be assimilated to two molecules linked head-to-head, which, in fact, is the arrangement found in the solid state. Therefore, as shown in Figure 8, the supramolecular organization of these species in the mesophase can be described as the self-assembly of antiparallel pairs arrayed in a $\mathrm{SmA}_{d}$ mesophase, similar to the mesophase reported for cyanobiphenyls [61]. 


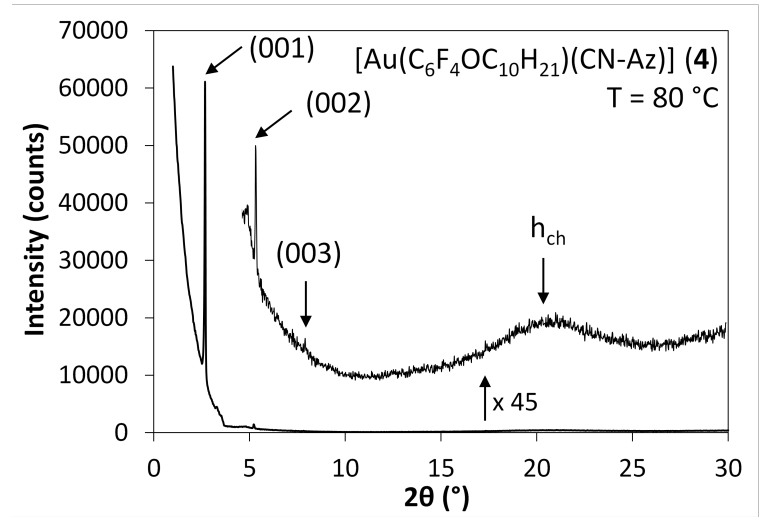

Figure 7. X-ray diffraction diffractogram of 4 , recorded at $80{ }^{\circ} \mathrm{C}$ on cooling from the isotropic liquid.

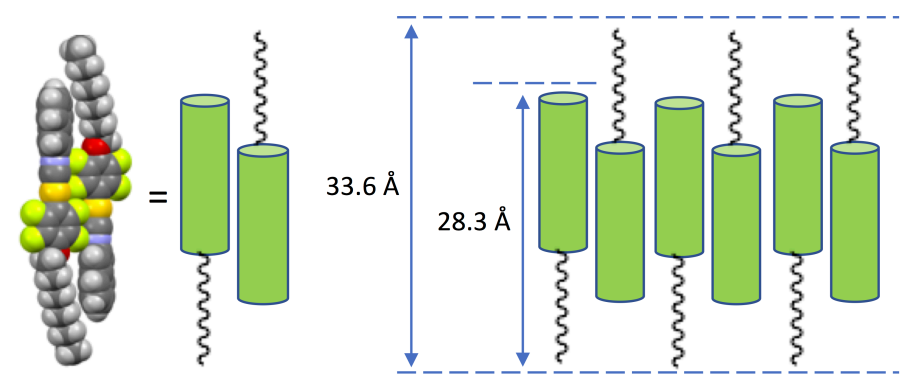

Figure 8. Schematic representation of the antiparallel pairing of $\mathbf{4}$ and their self-assembly into a partial bilayer SmA phase.

It should be noted that for compound $\mathbf{5}$, due to the narrow mesophase range, the melting and clearing transitions appear overlapped in the DSC scans. However, its mesomorphic behavior displaying a SmA mesophase is confirmed by the texture observed by POM (Figure 6b) and by XRD data. The diffractogram recorded at $164^{\circ}$ (Figure S61) only contains one sharp X-ray diffraction line associated with the 001 plane, as frequently observed for SmA phases with positional disorder of molecules along the normal to the layer in SmA [61], as well as the characteristic broad scattering maximum in the high-angle region corresponding to the molten alkyl chains. 
Regarding the structural and geometrical parameters responsible for mesophase induction in $\mathbf{5}$, they are similar to those of the rest of the mesomorphic compounds $\mathbf{4}$ and $\mathbf{8}$. It displays a no planar structure, the alkoxy chain is not collinear with the molecular core and its crystal packing shows a layered structure with nanosegregation between molten chains and aromatic parts.

Although the factors that drive the appearance of a liquid crystal phase are many and difficult to analyze, data from the X-ray diffraction structures can help to understand the behavior observed.

As discussed above, the mononuclear isocyanide complexes without a long substituent (non-mesomorphic 1, 2, and 7) have a nearly planar structure where the aromatic rings of the ligands are practically coplanar. In contrast, in their analogous complexes bearing a long chain (3-5 and 8), the mean planes of the two ligands are arranged twisted relative to each other, losing the molecular planarity. In general, more planar molecules should lead to more compact packing and stronger interactions than nonplanar ones. Consequently, the presence of a long substituent in these molecules produces a decrease of the melting points, and promotes the appearance of liquid crystal behavior.

The effect of the chain is, however, more than the simple rupture of the molecular planarity. In fact, the homologous complexes $\mathbf{3}$ and $\mathbf{4}$ bearing long substituents, although of somewhat different lengths, display very different behavior. The octyloxy derivative $\mathbf{3}$ is not mesomorphic, whereas the decyloxy analogous $\mathbf{4}$ is liquid crystal.

The alkyl chain is extended in all the complexes, but forming a different angle with the long molecular axis so that the mesomorphic complexes $(4,5$ and 8$)$ have a bent molecular 
architecture. In contrast, the non-mesomorphic complex $\mathbf{3}$ has a rod-like shape (Figures 1 and S1).

Molecules tend to be packed in the most efficient way. For the compounds under discussion that display mesomorphic behavior the packing consists of a lamellar arrangement, where a microsegregation of aromatic units and flexible chains is produced (Figures 5, S2 and S5). It is structurally similar to a conventional SmA mesophase with the long molecular axes orthogonal to the layers. In contrast, for the non-mesomorphic 3 the crystal packing shows a non-layered structure with the molecules arranged in an antiparallel disposition, where each molecule is shifted from the previous one, generating some mixing of the aromatic and aliphatic parts (Figure 4).

When these compounds are heated, the long alkyl chains melt at first to form a soft part, but its effect is not the same in the two types of molecular packing. In $\mathbf{3}$, where there is interpenetration of aromatic and aliphatic parts, the melting of the chains produces the breaking up of the crystalline structure to give rise to an isotropic liquid. In contrast, in the layered packing with microsegregation of aromatic and aliphatic parts, the melting of the chains preserves the self-assembly of the central cores so that a smectic mesomorphism is induced.

\subsection{Photophysical studies.}

The UV-Vis absorption and fluorescence data for the free isocyanide $\mathbf{C N}-\mathbf{A z}$ and the $\mathrm{Au}(\mathrm{I})$ complexes 1-8 in dichloromethane solution are summarized in Table S4.

The electronic absorption spectra of the free isocyanide and its gold complexes are all very similar, displaying a spectral pattern with absorption bands and extinction coefficients typical of the azulene moiety (Figure 8 ). 

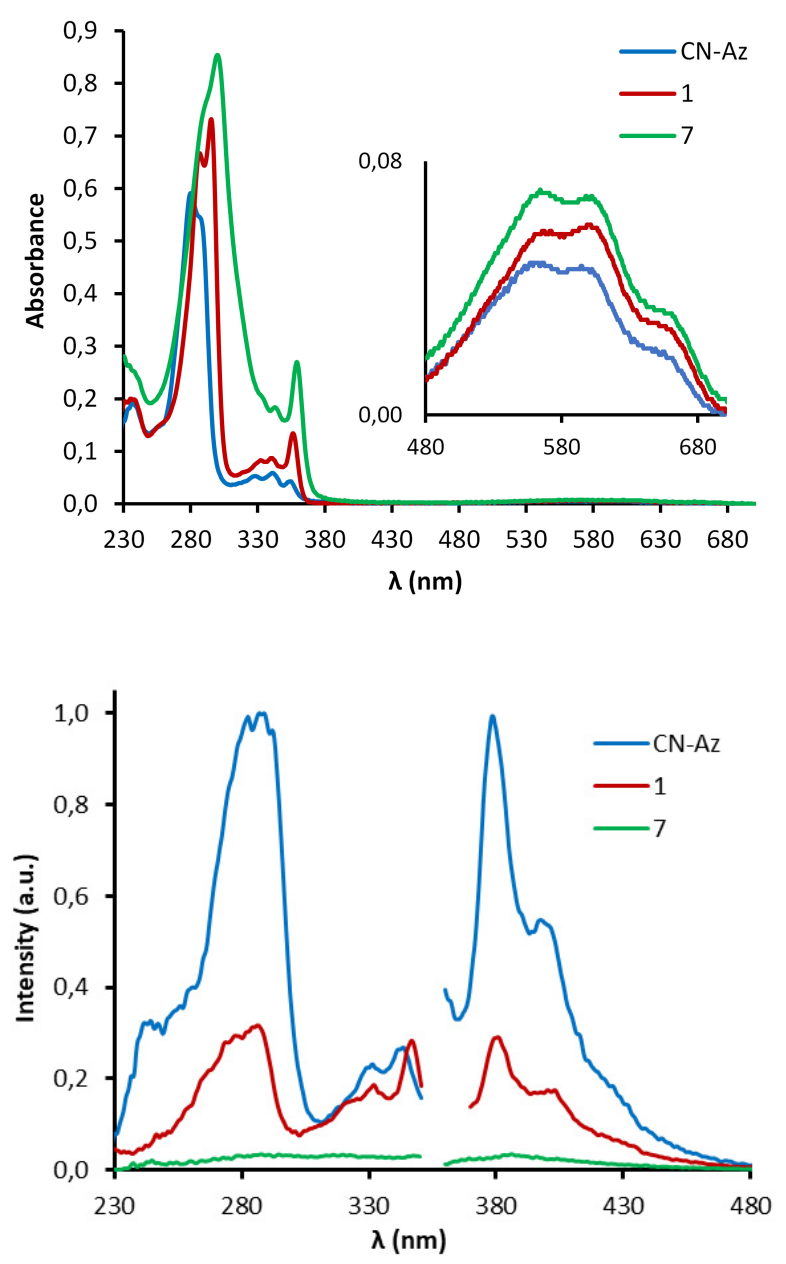

Figure 8. UV-Visible (up) and normalized luminescence (down) spectra of the free ligand $\mathbf{C N}-\mathbf{A z}$, the gold complexes $[\mathrm{AuCl}(\mathrm{CN}-\mathrm{Az})](\mathbf{1})$, and $\left[\mathrm{Au}\left(\mathrm{CCC}_{6} \mathrm{H}_{4} \mathrm{COOCH}_{3}\right)(\mathrm{CN}-\mathrm{Az})\right](7)$ in dichloromethane solution $\left(10^{-5} \mathrm{M}\right)$ at $298 \mathrm{~K}$.

The spectra show a weak and structured absorption in the visible region with $\lambda_{\max }$ ranging from 530 to $630 \mathrm{~nm}$, which is assigned to the $\mathrm{HOMO} \rightarrow$ LUMO excitation [47]. The coordination of the isocyanide ligand to the metal center produces a slight bathochromic shift $\left(150-400 \mathrm{~cm}^{-1}\right)$, because of the stabilization of LUMO relative to HOMO, in accordance with the higher electron withdrawing character of the coordinated isocyanide group on the azulene core [25].

The free isocyanide exhibits a weak fluorescent emission $(\Phi=0.33 \% ; \tau=1.1 \pm 0.1 \mathrm{~ns})$ at room temperature in dichloromethane solution, which has not been previously reported. 
This emission has a well-defined vibronic fine structure with a vibrational spacing of $\sim 1260$ $\mathrm{cm}^{-1}$, related to the $v(\mathrm{C}=\mathrm{C})$ frequency of the azulene core. The emission maximum wavelength appears at $379 \mathrm{~nm}$ (Figure 8, down), which is typical of fluorescent azulene derivatives involving $\mathrm{S}_{2}-\mathrm{S}_{0}$ transitions [62,63]. In the solid state (room temperature or $77 \mathrm{~K}$ ) the luminescence is practically lost, as observed frequently in aromatic compounds [64], including isocyanides [53a]. In the metal complexes, the profile of the emission spectra is completely similar to that of the free isocyanide, but the intensity of the emission is drastically reduced.

In order to confirm the nature of the absorption and emission spectra, the free isocyanide ligand and the chlorogold derivative (1), chosen as a representative complex, were studied theoretically by means of density functional and time-dependent density functional theory (TD-DFT) calculations. Computational details can be found in the Experimental section (SM). The ground-state geometry was optimized at the B3LYP level with no significant changes in distances and angles from the structure determined by x-ray diffraction (see Table S5 in the SM).

The calculated absorption energies associated with their dominant orbital excitations and oscillator strengths, together with the experimental results are given in Tables 2 and 3 for the free isocyanide and the chloro-gold complex, respectively. When the isocyanide ligand is coordinated to the gold fragment to give the gold complex, DFT calculations predict the bathochromic shift experimentally observed, in accordance with the higher electron withdrawing character of the coordinated isocyanide group on the azulene core. These results agree with those reported previously for the isocyanoazulene ligand and related chromium complexes [47]. 
Table 2. Dominant orbital excitations, calculated excited energies, and oscillator strength (f) from TD-DFT calculations for $\mathbf{C N}-\mathbf{A z}$.

\begin{tabular}{|l|l|l|l|l|l|l|}
\hline State & Excitation & Coef. & $\mathrm{E}_{\text {calc }}(\mathrm{eV})$ & $\lambda_{\text {calc }}(\mathrm{nm})$ & $f$ & $\lambda_{\text {exp }}(\mathrm{nm})$ \\
\hline $\mathrm{S}_{1}$ & HOMO-1 $\rightarrow$ LUMO+1 & -0.10 & 2.43 & 511 & 0.0148 & 556 \\
& HOMO $\rightarrow$ LUMO & 0.70 & & & & \\
\hline $\mathrm{S}_{2}$ & HOMO-1 $\rightarrow$ LUMO & 0.55 & 3.62 & 343 & 0.0431 & 341 \\
& HOMO $\rightarrow$ LUMO+1 & 0.44 & & & & \\
\hline $\mathrm{S}_{4}$ & HOMO-1 $\rightarrow$ LUMO & -0.44 & 4.65 & 267 & 1.6036 & 280 \\
& HOMO $\rightarrow$ LUMO+1 & 0.55 & & & & \\
\hline
\end{tabular}

Table 3. Calculated excited energies, dominant orbital excitations, and oscillator strength (f) from TD-DFT calculations for $[\mathrm{AuCl}(\mathrm{CN}-\mathrm{Az})](\mathbf{1})$.

\begin{tabular}{|l|l|l|l|l|l|l|}
\hline State & Excitation & Coef. & $\mathrm{E}_{\text {calc }}(\mathrm{eV})$ & $\lambda_{\text {calc }}(\mathrm{nm})$ & $f$ & $\lambda_{\text {exp }}(\mathrm{nm})$ \\
\hline $\mathrm{S}_{1}$ & HOMO $\rightarrow$ LUMO & 0.69 & 2.36 & 525 & 0.0170 & 567 \\
\hline $\mathrm{S}_{2}$ & HOMO-1 $\rightarrow$ LUMO & 0.61 & 3.57 & 348 & 0.2351 & 357 \\
& HOMO $\rightarrow$ LUMO+1 & -0.36 & & & & \\
\hline $\mathrm{S}_{8}$ & HOMO-3 $\rightarrow$ LUMO & 0.44 & 4.60 & 269 & 1.3529 & 296 \\
& HOMO-1 $\rightarrow$ LUMO & 0.26 & & & & \\
& HOMO-1 $\rightarrow$ LUMO+3 & 0.18 & & & & \\
& HOMO $\rightarrow$ LUMO+1 & 0.45 & & & & \\
\hline
\end{tabular}

The frontier molecular orbital compositions of both compounds $(\mathbf{C N}-\mathbf{A z}$ and 1) are collected in Figure 9. It can be seen that in both cases the highest occupied molecular orbitals (HOMOs) are mainly centred in the azulene group. The LUMO for the free ligand is extended over the whole molecule, including the isocyano group, while in the case of the complex 1 the LUMO is very similar with a small contribution from the gold atom. 


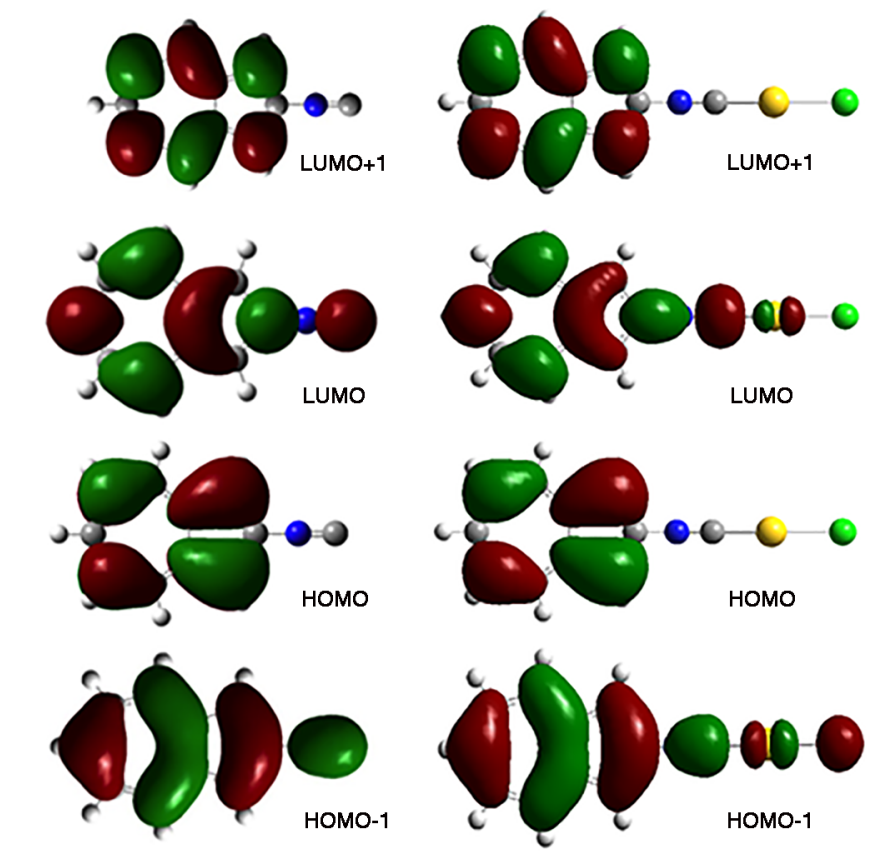

Figure 9. Frontier molecular orbitals for 2-Isocyanoazulene $(\mathbf{C N}-\mathbf{A z})($ left $)$ and $[\mathrm{AuCl}(\mathrm{CN}-$ Az)] (1) [ (right).

The experimental fluorescence corresponds to the calculated $\mathrm{S}_{2} \rightarrow \mathrm{S}_{0}$ emission in both cases, where the $\mathrm{S}_{2}$ excited states are derived from a combination of the HOMO $\rightarrow$

LUMO+1 and HOMO-1 $\rightarrow$ LUMO transitions (Table S6). As previously reported, the large energy difference between the $\mathrm{S}_{1}$ and the $\mathrm{S}_{2}$ states $\left(\Delta \mathrm{E}\left(\mathrm{S}_{2}-\mathrm{S}_{1}\right)\right)$ explains the non accordance of the emission of this kind of azulene derivatives with Kasha's rule [65]. Moreover, the decrease of the emission intensity observed upon coordination of the isocyanide to the gold fragment can be explained by the corresponding decrease in the calculated $\Delta \mathrm{E}\left(\mathrm{S}_{2}-\mathrm{S}_{1}\right)$, which favors nonradiative deactivation processes.

\section{Conclusions}

We have prepared a new series of highly blue-colored and emissive metal complexes based on 2-isocyanoazulene gold compounds of the type $[\mathrm{AuX}(\mathrm{CN}-\mathrm{Az})](\mathrm{X}=$ halide, 
perhalophenyl or alkynyl) and $\left[\mu-4,4^{\prime}-\mathrm{C}_{6} \mathrm{~F}_{4} \mathrm{C}_{6} \mathrm{~F}_{4}\{\mathrm{Au}(\mathrm{CN}-\mathrm{Az})\}_{2}\right]$ of potential interest in display applications or sensors. The single crystal X-ray data show that in homologous compounds, the introduction of a long substituent in the system produces a loss of molecular planarity. Although the free 2-isocyanoazulene is not a liquid crystal itself, the gold complexes $\mathbf{4 , 5}$ and $\mathbf{8}$, bearing a $\mathrm{C}_{10}$ hydrocarbon chain, display mesomorphic behavior, in which mesophase formation is driven by nanosegregation between molten chains and aromatic parts. The supramolecular organization of these metal complexes in the mesophase can be described as the self-assembly of antiparallel pairs arrayed in a partial bilayer structure $\mathrm{SmA}_{\mathrm{d}}$.

The free isocyanoazulene ligand shows a fluorescent emission centered on the azulene group, which is largely diminished upon coordination to the gold fragment. In both cases (ligand and complexes) the experimental fluorescence corresponds to the calculated $\mathrm{S}_{2} \rightarrow \mathrm{S}_{0}$ emission. The decrease in the emission intensity in the gold complexes is understood on the basis of a decrease in $\Delta \mathrm{E}\left(\mathrm{S}_{2}-\mathrm{S}_{1}\right)$, which favors nonradiative deactivation processes.

Acknowledgments. This work was sponsored by the Ministerio de Ciencia e Innovación (Project CTQ2017-89217-P) and the Junta de Castilla y León (Project VA038G18). We thank Prof. P. Espinet for helpful discussions. E. D. thanks the Spanish MECD for her FPU contract. M. B. thanks the Junta de Castilla y León for a PhD grant.

\section{Supplementary material}


Materials and methods. Full details of synthetic methods, spectroscopic and analytical data for the new compounds. ${ }^{1} \mathrm{H},{ }^{19} \mathrm{~F}$ and ${ }^{13} \mathrm{C}\left\{{ }^{1} \mathrm{H}\right\}$ NMR spectra of all new compounds.

MALDI-TOF mass spectra, X-ray data and computational details.

\section{References}

[1] Preethalayam P, Krishnan KS, Thulasi S, Chand SS, Joseph J, Nair V, Jaroschik F, Radhakrishnan KV. Recent Advances in the Chemistry of Pentafulvenes. Chem Rev 2017;117:3930-3989. https://doi.org/10.1021/acs.chemrev.6b00210

[2] Wang F, Lai Y-H, Han M-Y. Stimuli-Responsive Conjugated Copolymers Having Electro-Active Azulene and Bithiophene Units in the Polymer Skeleton: Effect of Protonation and p-Doping on Conducting Properties. Macromolecules 2004;37:32223230. https://doi.org/10.1021/ma035335q

[3] Cristian L, Sasaki I, Lacroix PG, Donnadieu B, Asselberghs I, Clays K, Razus AC. Donating Strength of Azulene in Various Azulen-1-yl-Substituted Cationic Dyes: Application in Nonlinear Optics. Chem Mater 2004;16:3543-3551. https://doi.org/10.1021/cm0492989

[4] Migalska-Zalas A, El kouari Y, Touhtouh S. Methodologies for computing UV-VIS spectra and nonlinear properties of azo-azulene derivatives. Opt Mater 2012;34:1639-1643. https://doi.org/10.1016/j.optmat.2012.03.021

[5] Salman H, Abraham H, Tal S, Meltzman S, Kapon M, Tessler N, Speiser S, Eichen Y. 1,3-Di(2-pyrrolyl)azulene: An Efficient Luminescent Probe for Fluoride. Eur J Org Chem 2005;11:2207-2212. https://doi.org/10.1002/ejoc.200500012

[6] López-Alled CM, Sanchez-Fernandez A, Edler KJ, Sedgwick AC, Bull SD, McMullin CL, Kociok-Köhn G, James TD, Wenk J, Lewis SE. Azulene-boronate esters: colorimetric indicators for fluoride in drinking water. Chem Commun 2017;53:12580-12583. http://dx.doi.org/10.1039/c7cc07416f.

[7] Zhou Y, Zou Q, Qiu J, Wang L, Zhu L. Rational Design of a Green-Light-Mediated Unimolecular Platform for Fast Switchable Acidic Sensing. J Phys Chem Lett 2018; 9:550-556. https://doi.org/10.1021/acs.jpclett.7b03233

[8] Dong J-X, Zhang H-L. Azulene-based organic functional molecules for optoelectronics. Chinese Chemical Letters 2016;27:1097-1104. https://doi.org/10.1016/j.cclet.2016.05.005

[9] Rao DL, Sun PL, Qin Y, Zhang P, Guo Z-X. Facile fabrication of 1,3-diazaazulene derivative nanowires. Materials Letters 2017;205:182-185. https://doi.org/10.1016/j.matlet.2017.06.075

[10] Xin H, Gao X. Application of Azulene in Constructing Organic Optoelectronic Materials: New Tricks for an Old Dog. ChemPlusChem 2017;82:945-956. https://doi.org/10.1002/cplu.201700039

[11] Xin H, Li J, Ge C, Yang X, Xuea T, Gao X. 6,6'-Diaryl-substituted biazulene diimides for solution-processable high-performance n-type organic semiconductors. Mater Chem Front 2018;2:975-985. https://doi.org/10.1039/c8qm00047f 
[12] Brettle R, Dunmur DA, Estdale S, Marson CM. Synthesis, Linear Dichroism and Mesogenic Properties of Substituted Azulenes. J Mater Chem 1993;3:327-331. https://doi.org/10.1039/JM9930300327

[13] Estdale SE, Brettle R, Dunmur DA, Marson CM. The azulene ring as a structural element in liquid crystals. J Mater Chem 1997;7:391-401. https://doi.org/10.1039/A606139G

[14] Fabian KHH, Elwahy AHM, Hafner K. Syntheses of mono-, di- and triethynylazulenes. Tetrahedron Lett 2000;41:2855-2858. https://doi.org/10.1016/S0040-4039(00)00308-7

[15] Mori A, Yokoo M, Hashimoto M, Ujiie S, Diele S, Baumeister U, Tschierske C. A Novel Biaxial Smectic Liquid Crystalline Phase Formed by Rodlike Molecules with a 1,3-Diazaazulene Skeleton. J Am Chem Soc 2003;125:6620-6621. https://doi.org/10.1021/ja034569m

[16] Ito S, Inabe H, Morita N, Ohta K, Kitamura T, Imafuku, K. Synthesis of Poly(6azulenylethynyl)benzene Derivatives as a Multielectron Redox System with Liquid Crystalline Behavior. J Am Chem Soc 2003;125:1669-1680. https://doi.org/10.1021/ja0209262

[17] Nakagawa K, Yokoyama T, Toyota K, Morita N, Ito S, Tahata S, Ueda M, Kawakami J, Yokoyama M, Kanai Y, Ohta K. Synthesis and liquid crystalline behavior of azulene-based liquid crystals with 6-hexadecyl substituents on each azulene ring. Tetrahedron 2010;66;8304-8312. https://doi.org/10.1016/j.tet.2010.08.012

[18] Rekka E, Chrysselis M, Siskou I, Kourounakis A. Synthesis of new azulene derivatives and study of their effect on lipid peroxidation and lipoxygenase activity. Chem Pharm Bull 2002;7:904-907. https://doi.org/10.1248/cpb.50.904

[19] López-Pérez B, Pepper HP, Ma R, Fawcett BJ, Pehere AD, Wei Q, Ji ZC, Polyak SW, Dai HQ, Song FH, Abell AD, Zhang LX, George JH. Biosynthetically Guided Structure-Activity Relationship Studies of Merochlorin A, an Antibiotic Marine Natural Product. ChemMedChem 2017;12:1969-1976. https://doi.org/10.1002/cmdc.201700451

[20] Zhou Y, Zhuang Y, Li X, Ågren, H, Yu L, Ding J, Zhu L. Selective Dual-Channel Imaging on Cyanostyryl-Modified Azulene Systems with Unimolecularly Tunable Visible-Near Infrared Luminescence. Chem Eur J 2017;23:7642-7647. https://doi.org/10.1002/chem.201700947

[21] Bennett S. The Chemistry and Manufacture of Cosmetics. 3rd ed. In: Schlossman ML, editor. Carol Stream, IL: Allured Publishing Corporation; 2002; Vol. 3, p 243.

[22] Yao J, Cai Z, Liu Z, Yu C, Luo H, Yang Y, Yang S, Zhang G, Zhang D. Tuning the Semiconducting Behaviors of New Alternating DithienyldiketopyrrolopyrroleAzulene Conjugated Polymers by Varying the Linking Positions of Azulene. Macromolecules 2015;48:2039-2047. https://doi.org/10.1021/acs.macromol.5600158

[23] Tetreault N, Muthyala RS, Liu RSH, Steer RP. Control of the Photophysical Properties of Polyatomic Molecules by Substitution and Solvation: The Second Excited Singlet State of Azulene. J Phys Chem A 1999;103:2524-2531. https://doi.org/10.1021/jp984407q

[24] El-Nahas AM, Staykov A, Yoshizawa K. Electrical Conductance and Diode-Like Behavior of Substituted Azulene. J Phys Chem C 2017;121:2504-2511. https://doi.org/10.1021/acs.jpcc.6b10339 
[25] Shevyakov SV, Li H, Muthyala R, Asato AE, Croney JC, Jameson DM, Liu RSH. Orbital Control of the Color and Excited State Properties of Formylated and Fluorinated Derivatives of Azulene. J Phys Chem A 2003;107:3295-3299. https://doi.org/10.1021/jp021605f

[26] Liu RSH, Muthyala RS, Wang X-S, Asato AE. Correlation of Substituent Effects and Energy Levels of the Two Lowest Excited States of the Azulenic Chromophore. Org Lett 2000;2:269-271. https://doi.org/10.1021/o1990324w

[27] Jamali S, Mousavi N, Bagherzadeh M, Kiaa R, Samouei H. Stimuli-responsive emissive behavior of 1- and 1,3-connectivities in azulene-based imine ligands: cycloplatination and Pt-Tl dative bond formation. Dalton Trans 2017;46:1132711334. https://doi.org/10.1039/c7dt02359f

[28] Cabeza JA, del Río I, Fernández-Colinas JM, García-Álvarez P, Miguel D. Reactivity of Indene, Fluorene, Azulene, and Acenaphthylene with a Basal-Edge-Bridged Square-Pyramidal Hexaruthenium Dihydride. Organometallics 2007;26:1414-1423. https://doi.org/10.1021/om061078c

[29] Churchill MR. Transition metal complexes of azulene and related ligands. Prog Inorg Chem 1970;11:53-98.

[30] Töfke S, Behrens U. Azulene as Unusual $\eta^{6}$-Ligand and as $\eta^{6}: \eta^{4}$-Bridge in MoComplexes. Angew Chem Int Ed Engl 1987;26:147-148. https://doi.org/10.1002/anie.198701471

[31] Wang F, Lai Y-H, Han MY. Post-Coordination of Multinuclear Transitional Metal Clusters to Azulene-Based Polymers: A Novel Strategy for Tuning Properties in $\pi$ Conjugated Polymers. Org Lett 2003;5:4791-4794.

https://doi.org/10.1021/o10357346

[32] Lash TD, Colby DA, Graham SR, Ferrence GM, Szczepura LF. Organometallic Chemistry of Azuliporphyrins: Synthesis, Spectroscopy, Electrochemistry, and Structural Characterization of Nickel(II), Palladium(II), and Platinum(II) Complexes of Azuliporphyrins. Inorg Chem 2003;42:7326-7338.

https://doi.org/10.1021/ic030166b

[33] Colby DA, Ferrence GM, Lash TD. Oxidative Metalation of Azuliporphyrins with Copper(II) Salts: Formation of a Porphyrin Analogue System with a Unique Fully Conjugated Nonaromatic Azulene Subunit. Angew Chem Int Ed 2004;43:1346-1349. https://doi.org/10.1002/anie.200353189

[34] Kurotobi K, Osuka A. Synthesis of meso-Azulenylporphyrins. Org Lett 2005;7:10551058. https://doi.org/10.1021/o10473360

[35] Lash TD. Out of the Blue! Azuliporphyrins and Related Carbaporphyrinoid Systems. Acc Chem Res 2016;49:471-482. https://doi.org/10.1021/acs.accounts.5b00523

[36] Weber L. Homoleptic Isocyanide Metalates. Angew Chem Int Ed 1998;37:15151517.

[37] Barybin MV, Meyers JJ, Neal BM. Renaissance of Isocyanoarenes as Ligands in Low-Valent Organometallics. In: Nenajdenko VG, editor. Isocyanide Chemistry. Applications in Synthesis and Material Science, Weinhheim, Germany:VCH; 2012.

[38] Tanabiki M, Tsuchiya K, Kumanomido Y, Matsubara K, Motoyama Y, Nagashima H. Nickel(II) Isocyanide Complexes as Ethylene Polymerization Catalysts. Organometallics 2004;23:3976-3981. https://doi.org/10.1021/om0498394 
[39] Robinson RE, Holovics TC, Deplazes SF, Lushington GH, Powell DR, Barybin M. V. First Isocyanoazulene and Its Homoleptic Complexes. J Am Chem Soc 2003;125:4432-4433. https://doi.org/10.1021/ja034706f

[40] Chico R, de Domingo E, Domínguez C, Donnio B, Heinrich B, Termine R, Golemme A, Coco S, Espinet P. High One-Dimensional Charge Mobility in Semiconducting Columnar Mesophases of Isocyano-Triphenylene Metal Complexes. Chem Mater 2017;29:7587-7595. https://doi.org/10.1021/acs.chemmater.7b02922

[41] Conejo-Rodríguez V, Peñas-Defrutos M, Espinet P. 4-Pyridylisocyanide gold(I) and gold(I)-plus-silver(I) luminescent and mechanochromic materials: the silver role. Dalton Trans 2019;48:10412-10416. https://doi.org/10.1039/c9dt01618j

[42] Bayón R, Coco S, Espinet P. Twist-Grain Boundary Phase and Blue Phases in Isocyanide Gold(I) Complexes. Chem Mater 2002;14:3515-3518. https://doi.org/10.1021/cm020246y

[43] Barybin MV. Nonbenzenoid aromatic isocyanides: New coordination building blocks for organometallic and surface chemistry. Coord Chem Rev 2010;254:1240-1252. https://doi.org/10.1016/j.ccr.2009.11.002

[44] Holovics TC, Robinson RE, Weintrob EC, Toriyama M, Lushington GH, Barybin MV. The 2,6-Diisocyanoazulene Motif: Synthesis and Efficient Mono- and Heterobimetallic Complexation with Controlled Orientation of the Azulenic Dipole. J Am Chem Soc 2006;128:2300-2309. https://doi.org/10.1021/ja053933+

[45] DuBose DL, Robinson RE, Holovics TC, Moody DR, Weintrob EC, Berrie CL, Barybin MV. Interaction of Mono- and Diisocyanoazulenes with Gold Surfaces: First Examples of Self-Assembled Monolayer Films Involving Azulenic Scaffolds. Langmuir 2006;22:4599-4606. https://doi.org/10.1021/la0532050

[46] Maher TR, Spaeth AD, Neal BM, Berrie CL, Thompson WH, Day VW, Barybin MV. Linear 6,6'-Biazulenyl Framework Featuring Isocyanide Termini: Synthesis, Structure, Redox Behavior, Complexation, and Self-Assembly on Au(111). J Am Chem Soc 2010;132:15924-15926. https://doi.org/10.1021/ja108202d

[47] Robinson RE, Holovics TC, Deplazes SF, Powell DR, Lushington GH, Thompson WH, Barybin MV. Five Possible Isocyanoazulenes and Electron-Rich Complexes Thereof: A Quantitative Organometallic Approach for Probing Electronic Inhomogeneity of the Azulenic Framework. Organometallics 2005;24:2386-2397. https://doi.org/10.1021/om0502180

[48] Fathi-Rasekh M, Rohde GT, Hart MD, Mason DH, Nakakita T, Zatsikha YV, Valiev RR, Barybin MV, Nemykin VN. Positional Isomers of Isocyanoazulenes as Axial Ligands Coordinated to Ruthenium(II) Tetraphenylporphyrin: Fine-Tuning Redox and Optical Profiles. Inorg Chem 2019;58:9316-9325. https://doi.org/10.1021/acs.inorgchem.9b1030

[49] Applegate JC, Okeowo MK, Erickson NR, Neal BM, Berrie CL, Gerasimchuk NN, Barybin MV. First $\pi$-linker featuring mercapto and isocyano anchoring groups within the same molecule: synthesis, heterobimetallic complexation and self-assembly on Au(111). Chem Sci 2016;7:1422-1429. https://doi.org/10.1039/c5sc04017e

[50] Coco S, Cordovilla C, Domínguez C, Espinet P. Luminescent gold(I) metallo-acids and their hydrogen bonded supramolecular liquid crystalline derivatives with decyloxystilbazole as hydrogen acceptor. Dalton Trans 2008;48:6894-6900. https://doi.org/10.1039/b811482j 
[51] Coco S, Espinet P. Pentafluorophenyl Complexes of Palladium and Platinum containing Chelating and Bridging $\mathrm{Fe}\left(\mathrm{C}_{5} \mathrm{H}_{4} \mathrm{PPh}_{2}\right)_{2}$ or $\mathrm{Fe}\left(\mathrm{C}_{5} \mathrm{H}_{4} \mathrm{SPh}\right)_{2}$ Ligands. J Organomet Chem 1994;484:113-118. https://doi.org/10.1016/0022-328X(94)87194$\underline{9}$

[52] Usón R, Laguna A. Recent Development in aryl gold chemistry. Coord Chem Rev 1986;70:1-50. https://doi.org/10.1016/0010-8545(86)80034-0

[53] Usón R, Laguna A, Vicente J, García J, Jones PG, Sheldrick GM. Preparation of three- and four-co-ordinate gold(I) complexes; crystal structure of bis $[o$ phenylenebis(dimethylarsine)]gold(I) bis(pentafluorophenyl)aurate(I). J Chem Soc Dalton Trans 1981;2:655-657. https://doi.org/10.1039/dt9810000655

[54] Coco S, Cordovilla C, Espinet P, Martín-Alvarez JM, Muñoz P. Dinuclear Gold(I) Isocyanide Complexes with Luminescent Properties, and Displaying Thermotropic Liquid Crystalline Behavior. Inorg Chem 2006;45:10180-10187. https://doi.org/10.1021/ic060702a

[55] Bayón R, Coco S, Espinet P. Gold Liquid Crystals Displaying Luminescence in the Mesophase and Short F ‥F Interactions in the Solid State. Chem Eur J 2005;11:1079-1085. https://doi.org/10.1002/chem.200400829; ibid. Chem. Eur. J., 2005, 11, 3500 (corrigendum). https://doi.org/10.1002/chem.200590040

[56] Lentijo S, Aullón G, Miguel JA, Espinet P. Highly fluorescent complexes with gold, palladium or platinum linked to perylene through a tetrafluorophenyl group. Dalton Trans 2013;42:6353-6365. https://doi.org/10.1039/c3dt32843k

[57] Vicente J, Chicote MT, Abrisqueta MD, Jones PJ. A novel type of alkynylgold(I) complex. Crystal and molecular structures of $\mathrm{PPN}[\mathrm{Au}(\mathrm{Ar})(\mathrm{C}$ equivalent to $\mathrm{CH})]$ [Ar $\left.=\mathrm{C}_{6} \mathrm{~F}_{5}, \mathrm{C}_{6} \mathrm{H}_{2}\left(\mathrm{NO}_{2}\right)(3)-2,4,6\right]$. Organometallics 2000;19:2629-2632. https://doi.org/10.1021/om9910322

[58] Fujisawa K, Okuda Y, Izumi Y, Nagamatsu A, Rokusha Y, Sadaike Y, Tsutsumi O. Reversible thermal-mode control of luminescence from liquid-crystalline gold(I) complexes. J Mater Chem C 2014;2:3549-3555. https://doi.org/10.1039/c3tc31973c

[59] Gray GW, Goodby JW. Smectic Liquid Crystals. Textures and Structures. Glasgow: Hill; 1984.

[60] Dierking I. Textures of Liquid Crystals. Weinheim: WILEY-VCH Verlag GmbH \& Co. KGaA; 2003.

[61] Yamamura Y, Tsuchiya R, Fujimura S, Hishida M, Saito K. Odd-Even Effect on Nematic SmAd Phase Boundary and SmAd Structure in Homologous Binary Systems of Cyanobiphenyl Mesogens: 4-Alkyl-4'-cyanobiphenyl (nCB) and 4-Alkoxy-4'cyanobiphenyl (nOCB). J Phys Chem B 2017;121:1438-1447. https://doi.org/10.1021/acs.jpcb.6b12977

[62] Zhang Y, Aslan K, Previte MJR, Geddes CD. Metal-enhanced S-2 fluorescence from azulene. Chem Phys Lett 2006;432:528-532.

https://doi.org/10.1016/j.cplett.2006.11.005

[63] Itoh T. Fluorescence and Phosphorescence from Higher Excited States of Organic Molecules. Chem Rev 2012;112;4541-4568. https://doi.org/10.1021/cr200166m; ibid Chem Rev 2014;114:6080 (corrigendum).

[64] Birks JB. Photophysics of Aromatic Molecules, John-Wiley: London, 1970.

[65] Murata S, Iwanaga C, Toda T, Kokubun H. Fluorescence Yields of Azulene Derivatives. Chem Phys Lett 1972;13(2):101-104. https://doi.org/10.1016/00092614(72)80054-X 